\title{
Determination Trace Levels of Vitamin C and Folic Acid in Urine Sample by Ultrasound-assisted Dispersive Liquid-Liquid Microextraction Method Coupled HPLC-UV
}

\author{
AKBAR AKBARI ${ }^{1}$, NARGES CHAMKOURI ${ }^{2 *}$ and ATEFEH ZADABDOLLAH ${ }^{2}$ \\ ${ }^{1}$ Abadan School of Medical Sciences, Abadan, Iran. \\ ${ }^{2}$ Student Research Committee, Abadan School of Medical Sciences, Abadan, Iran. \\ *Corresponding author E-mail: narges.chamkouri@ chmail.ir \\ http://dx.doi.org/10.13005/ojc/320623
}

(Received: October 6, 2016; Accepted: November 12, 2016)

\begin{abstract}
A new, rapid and highly sensitive and rapid method was proposed for the simultaneous determination trace levels of vitamin $\mathrm{C}$ and folic acid in the human urine samples. The inûuence affecting factors on the UA-DLLME such as type and volume of the dispersive and extraction solvent, $\mathrm{pH}$, ionic strength and temperature of sample solution, sonication condition investigated and optimized. Under the optimized extractions, relative standard deviations (RSD) of the analyses less than $6 \%$ $(\mathrm{n}=3)$ and detection limit of $1.65-2.05 \mathrm{ng} \mathrm{mL}^{-1}$ respectively. USAEME - HPLC-UV was successfully applied for the simultaneous determination of trace levels of vitamin $\mathrm{C}$ and folic acid in human urine Samples.
\end{abstract}

Keywords: Dispersive liquid-liquid microextraction, Folic acid, HPLC, Vitamin C, Ultrasound-assisted.

\section{INTRODUCTION}

Vitamin $\mathrm{C}$ and folic acid are water-soluble vitamins, necessary for a healthy diet. They are involved in tissue growth and normal cell function. They also serve as cofactors for at least eight enzymatic reactions, performe antioxidant activity as well as have protective roles for the cell membranes, and are crucial for maintaining optimal health ${ }^{1-3}$. Many analytical methods including spectrophotometry ${ }^{4}$, spectrofluorimetry ${ }^{5}$, chemiluminescence ${ }^{6,7}$, capillary electrophoresis ${ }^{8,9}$, electrochemical methods ${ }^{10}$ and HPLC method ${ }^{11,12}$ have been reported for the determination of vitamin $\mathrm{C}$ and folic acid. Most of these methods are expensive instruments and have a high limit of detection (LOD).

In 2006, a new microextraction technique called dispersive liquid-liquid microextraction (DLLME) was introduced ${ }^{13,14}$. It is as an effective preconcentration and separation of technique among these microextraction method for inorganic and organic species determination ${ }^{15,16}$. This method has a higher enrichment factor, is safe for use with hazardous samples, has a minimal cost because it consumes little reagent, is environmentfriendly, 
low cost and easier to incorporate into automated analytical methods ${ }^{17,18}$. The goal of this research was to develop a new and rapid method for the simultaneous determination of vitamin $\mathrm{C}$ and folic acid in human urine samples by high performance liquid chromatography-ultraviolet detection (HPLC-UV) after preconcentration by UA-DLLME. Experimental factors affecting the extraction recoveries, including type and volume of extraction and disperser solvents, $\mathrm{pH}$, ionic strength and temperature of sample solution, and sonication time were considered and optimized. This method was aimed to investigate and validate a method for the determination of $\mathrm{C}$ vitamin concentrations in human urine and synthesis samples by HPLC after optimization by UA-DLLME method.

\section{EXPERIMENTAL}

\section{Chemicals and reagents}

The analytical-reagent grade of vitamins (>99\%) were purchased from Sigma-Aldrich (Steinheim, Germany). HPLC-grade methanol was purchased from Fisher Scientific (Waltham, MA, USA). Standard stock solutions were prepared by dissolving vitamin in deionized water. Working standard solutions at different concentrations were prepared freshly by mixing the appropriate volumes of the stock solutions and diluting with deionized water Millipore, Bedford, MA, USA).

\section{Instrumentation and software}

The chromatography runs for the separation and determination of vitamin $\mathrm{C}$ and folic acid were performed using a Shimadzu Corporation HPLC (Japan) system equipped with UV-VIS detector (SPD-20Avp), LPG system (LC-20ADvp), micro vacuum degasser and a $\mathrm{C}_{18}$ - ODS column $(250 \times 4.0 \mathrm{~mm}, 5 \mathrm{im})$ from Shim pack VP (Japan). UV detection was performed at 200 to $300 \mathrm{~nm}$. The mobile phase was a mixture of $60 \%$ methanol and $40 \% 0.03 \mathrm{M}$ phosphate buffer $\mathrm{pH} 2.5$ at a flow of 1 $\mathrm{mL} \mathrm{min}^{-1}$ at $25 \mathrm{C}$. The $\mathrm{pH}$ was measured using a $\mathrm{pH}$ meter (Metrohm 827, Switzerland) combined with a glass electrode.

\section{Preparation of sample}

Actual urine samples were supplied from sick volunteers in Taleghani Medical Center (Abadan, Iran) and were kept frozen at $-10^{\circ} \mathrm{C}$ before analysis.
The frozen urine samples were thawed at room temperature and centrifuged for $10 \mathrm{~min}$ at 4000 rpm in order to white lipid solid was sedimented in the bottom of the conical test tube. For protein precipitation a solution containing $50 \mu \mathrm{L}$ of $1 \%$ trichloroacetic acid (TCA) was added to $1.0 \mathrm{~mL}$ of human urine. This mixture was shaken for $10 \mathrm{~s}$ and then filtred through $0.45 \mu \mathrm{m}$ nylon ûlter membrane. Then $0.5 \mathrm{~mL}$ filterd sample was transferred to a new tube and was alkalinized with $200 \mu \mathrm{L}(\mathrm{NaOH}$ $1 \mathrm{~mol} \mathrm{~L}^{-1}$ ) for the hydrolysis of acyl glucuronic acid conjugates; thereafter it was neutralized with 200 $\mu \mathrm{L}\left(\mathrm{HCl} 1 \mathrm{~mol} \mathrm{~L}^{-1}\right)$. The matrix effects were lowered by two times dilution of urine sample andwas then directly subjected to UA-DLLME procedure.

\section{UA-DLLME procedure}

A $5 \mathrm{~mL}$ aqueous sample solution ( $\mathrm{pH}$ 3.5) with the ionic strength of $0.05 \%(w / v) ~ N a C l$, containing $25 \mathrm{ng} \mathrm{mL}^{-1}$ of vitamin $\mathrm{C}$ and folic acid were placed in a $10.0 \mathrm{~mL}$ screw cap glass test tube with conical bottom. A mixture of $50 \mu \mathrm{L}$ of methanol containing $100 \mu \mathrm{L}$ carbon tetrachloride were rapidly injected into the sample solution with a $1.0 \mathrm{~mL}$ glass syringe and then the glass test tube was immersed in an ultrasonic water bath for 4 min to enhance the extraction of vitamin $\mathrm{C}$ and folic acid from aqueous solution into the microdroplets of carbon tetrachloride. Then the mixture was centrifuged at $5500 \mathrm{rpm}$ for $4 \mathrm{~min}$ in order to obtain the extraction solvent at the bottom of the centrifuge tube. The sedimented phase was completely transferred to another test tube using $100 \mu \mathrm{L}$ microsyringe (Hamilton) and blown to dryness with a mild nitrogen stream. After slowly discarding the aqueous solution, the resulting droplet and lipidic solid were dissolved at $20 \mu \mathrm{L}$ with HPLC grade methanol and then filtrated through a $0.45 \mu \mathrm{m}$ membrane to throw out the white floccule from the extract of urine.

\section{RESULTS AND DISCUSSION}

It is well known that the extraction recoveries of UA-DLLME can be affected by different factors, such as types and volume of extraction solvent, $\mathrm{pH}$ and ionic strength of sample solution, extraction time and temperature as well as centrifugation time. The optimization was performed for high extraction recovery. Samples of $5 \mathrm{~mL}$ of aqueous solutions containing $25 \mathrm{ng} \mathrm{mL}^{-1}$ of vitamin $\mathrm{C}$ and folic acid were 
used to investigate the best extraction conditions for the proposed UA-DLLME method.

\section{Selection of extraction and disperser solvents}

In UA-DLLME, the selection of the most suitable extraction and dispersive solvents is the prerequisite condition which needs to be considered ${ }^{14}$ . In the selection of extraction solvent, several factors should be considered: (1) low solubility in water, (2) higher density than water, (3) high extraction recoveries of interested compounds and (4) good chromatographic behavior. Taking into account these characteristics, four high density solvents such as dichloromethane $\left(\mathrm{CH}_{2} \mathrm{Cl}_{2}: 1.32 \mathrm{gmL}^{-1}\right)$, chloroform $\left(\mathrm{CHCl}_{3}: 1.47 \mathrm{gmL}^{-1}\right)$, carbon tetrachloride $\left(\mathrm{CCl}_{4}: 1.59\right.$ $\left.\mathrm{gmL}^{-1}\right)$, and chlorobenzene $\left(\mathrm{C}_{6} \mathrm{H}_{5} \mathrm{Cl}: 1.11 \mathrm{gmL}^{-1}\right)$ were investigated for this purpose. The disperser solvent would influence the formation of the cloudy solution and the produced infinite interface increases the mass transfer. The dispersive solvent must be miscible with both aqueous and organic phases. Acetonitrile, methanol, ethanol and acetone were evaluated to select the best dispersive solvent in this study. It was found that the maximal peak area was attained when carbon tetrachloride and methanol solvents were used as extraction and dispersive solvents, respectively. In order to study the effect of extraction solvent volume on the extraction efficiency, different volumes of $\mathrm{CCl}_{4}(20-120 \mu \mathrm{L}$ at $10 \mu \mathrm{L}$ interval) and a $50 \mu \mathrm{L}$ of methanol were tested. According to the obtained results, with the increase of $\mathrm{CCl}_{4}$ volume $(90-100 \mu \mathrm{L})$, the peak areas of vitamin $\mathrm{C}$ and folic acid increased; however, more increasing the volume of $\mathrm{CCl}_{4}$ than $100 \mu \mathrm{L}$, the peak areas was decreased. As a result, $100 \mu \mathrm{L}$ of $\mathrm{CCl}_{4}$ was used as extraction solvent for further experiments. The influence of the volume of the methanol was investigated by changing its volume from $10-60 \mu \mathrm{L}$ (at $10 \mu \mathrm{L}$ interval). It was found that the extraction efficiency is raised with increasing methanol to 50 $\mu \mathrm{L}$ and then decreased by increasing the volume of methanol for the vitamin $\mathrm{C}$ and folic acid. The reason for this could be that at a low volume of methanol, a cloudy state could not be formed well, therefore, resulting in a low recovery. At a higher volume of methanol, the solubility of the vitamin $\mathrm{C}$ and folic acid in water was increased, leading to the decreased extraction efficiency. Based on the experimental results, $50 \mu \mathrm{L}$ of methanol was chosen in subsequent experiment.

Table 1: Analytical performance of UA-DLLME method for determination of vitamin $\mathrm{C}$ and folic acid in blank urine

\begin{tabular}{cccccc}
\hline Analyte & $\mathbf{r}^{2}$ & $\begin{array}{c}\text { LOD }^{\mathrm{a}} \\
\left(\mathbf{n g ~ m L}^{-1}\right)\end{array}$ & $\begin{array}{c}\text { LOQ }^{\mathrm{b}} \\
\left(\mathbf{n g ~ m L}^{-1}\right)\end{array}$ & $\begin{array}{c}\text { LR }^{\mathbf{c}} \\
\left(\mathbf{n g ~ m L}^{-1}\right)\end{array}$ & $\begin{array}{c}\text { RSD } \\
(\mathbf{n}=6)\end{array}$ \\
\hline Vitamin C & 0.997 & 1.69 & 5.63 & $7-500$ & 3.7 \\
Folic acid & 0.998 & 2.05 & 6.83 & $8-500$ & 5.3 \\
\hline
\end{tabular}

a LOD: limit of detection; ${ }^{b}$ LOQ: limit of quantification; ${ }^{c}$ LR: linear range

Table 2: Comparison of the UA-DLLME with other methods for determination of Vitamin $\mathbf{C}$ and folic acid

\begin{tabular}{|c|c|c|c|c|c|c|}
\hline Method & Analyte & Matrix & $\begin{array}{c}\text { LDR } \\
\left(\mathrm{ngmL}^{-1}\right)\end{array}$ & $\begin{array}{c}\text { LOD } \\
\left(\mathrm{mg} \mathrm{L}^{-1}\right)\end{array}$ & RSD\% & Ref \\
\hline HPLC-MS/MS & Folic acid & Plasma & $0.249-19.9$ & - & 15 & 19 \\
\hline \multirow[t]{2}{*}{ HPLC-DAD } & Vitamin C & Mineral & $410.2-1230.7$ & 137 & - & 20 \\
\hline & Folic acid & Tablets & 2952-8856 & 10 & & \\
\hline Ion-exclusion HPLC-UV & Vitamin C & Plasma & 5-200 & 0.306 & - & 21 \\
\hline \multirow[t]{2}{*}{ UA-DLLME-HPLC-UV } & Vitamin C & Urine & $7-550$ & 1.69 & 3.7 & This \\
\hline & Folic acid & & $8-500$ & 2.05 & 5.3 & work \\
\hline
\end{tabular}




\section{Effect of $\mathrm{pH}$ on extraction efficiency}

The $\mathrm{pH}$ of sample solution is an important factor and can be affected on the extraction recoveries. Therefore, its effect was evaluated in the range of $\mathrm{pH} 2-8$. According to the obtained results, extraction recovery is maximum at $\mathrm{pH}=3.5$. This could be explained by the $\mathrm{pK}_{\mathrm{a}}$ values of vitamin $\mathrm{C}$ and (4.5) and folic acid (3.5). Thus, when the $\mathrm{pH}$ is around the $\mathrm{pK}_{\mathrm{a}}$ value of the analyte, it is mainly in its neutral form and can easily extract into the organic phase.

\section{lonic strength}

The influence of ionic strength on the performance of DLLME method was investigated by adding different amounts of $\mathrm{NaCl}(0-2 \% \mathrm{w} / \mathrm{v})$.
The results indicated that the extraction effciency decreases, with addition of salt up to $0.05 \%(\mathrm{w} / \mathrm{v})$ salt content. Therefore, $0.05 \%(\mathrm{w} / \mathrm{v}) \mathrm{NaCl}$ was chosen in further experiment.

\section{Effect of extraction time and temperature}

In this method, for improve the homogeneity, ultrasound- and shaking-assisted methods were investigated with a series of experiments. The effect of ultrasonic time on the extraction efficiency was investigated in the range of $0-5 \mathrm{~min}$. The maximum recovery was obtained for ultrasonication of 4.0 min and no improvement was achieved by further sonication time. This was probably due to the fact that the ultrasonic water bath could generate the emulsion quickly and rapidly make a very large contact surface

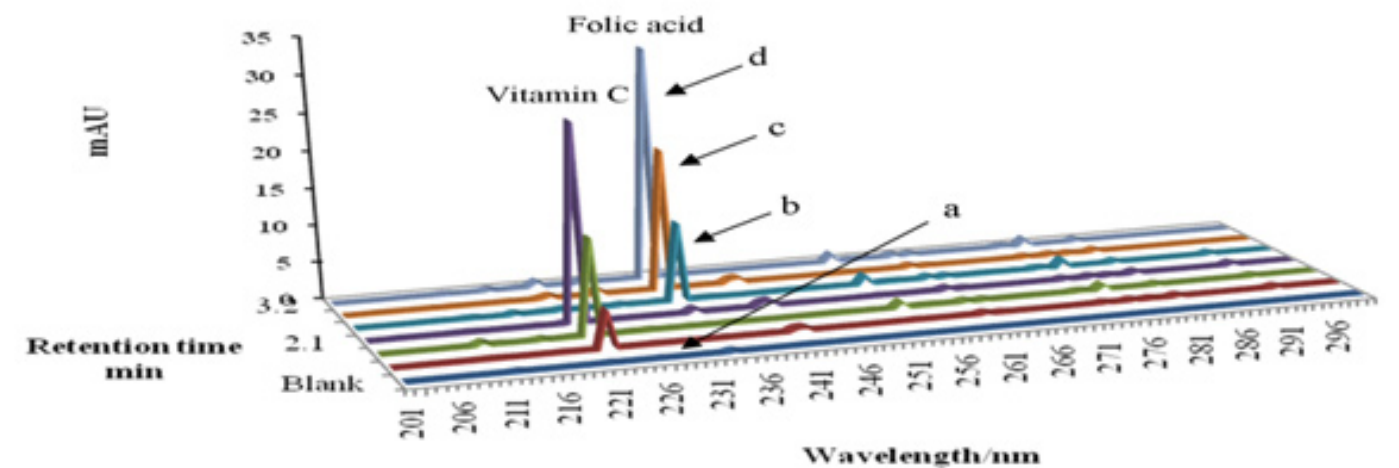

Fig. 3: Chromatograms of vitamin C and folic acid by HPLC at optimum extraction condition (a) blank urine; (b), (c) and (d) blank urine samples spiked with 15, 30 and $45 \mathrm{ng} \mathrm{mL}^{-1}$ of vitamin $\mathrm{C}$ and folic acid, respectively

Table 3: Extraction recoveries of vitamin C and folic acid from actual urine samples with the UA-DLLME method $(n=3)$

\begin{tabular}{lccc}
\hline Analyte & $\begin{array}{c}\text { Spiked } \\
\left(\mathbf{n g ~ m L} \mathbf{~ m}^{-1}\right)\end{array}$ & $\begin{array}{c}\text { Found } \\
\left(\mathbf{n g ~ m L} \mathbf{~ m}^{-1}\right)\end{array}$ & $\begin{array}{c}\text { ER } \pm \text { RSD } \\
\text { (\%) }\end{array}$ \\
\hline Vitamin C & 0.0 & 18.3 & - \\
& 15.0 & 32.7 & $96.2 \pm 4.5$ \\
& 30.0 & 46.8 & $95.1 \pm 4.1$ \\
Folic acid & 45.0 & 62.5 & $98.2 \pm 3.8$ \\
& 0.0 & 25.3 & - \\
& 15.0 & 39.4 & $94.3 \pm 5.2$ \\
& 30.0 & 54.5 & $97.3 \pm 4.7$ \\
& 45.0 & 68.9 & $96.8 \pm 4.2$ \\
\hline
\end{tabular}

area between the extraction solvent and aqueous phase. Therefore, 4 min was found to be the optimum extraction time. Temperature affects the solubility of organic solvent in water, distribution coefficients and mass transfer of the target analytes. The effect of extraction temperature on extraction recoveries was evaluated over the range of 15 to $35^{\circ} \mathrm{C}$. Results show (Fig. 2.) that increase in solution temperature decreases the amount of analytes extracted. Thus, $25^{\circ} \mathrm{C}$ was selected as optimum temperature.

\section{Analytical features of proposed method}

Under the optimized conditions, the analytical features of the developed method including linearity (correlation coefficient $\left(r^{2}\right)$ and linear range 
(LR)), limit of quantiûcation (LOQ), limit of detection (LOD), and precision (RSD\%) were evaluated. LOD and LOQ were calculated as 3 and 10 times of the standard deviation of blank signal divided by the slope of the calibration curve, respectively. The calibration curves for the vitamin $\mathrm{C}$ and folic acid showed good linearity in the concentration range $7-500 \mathrm{ng} \mathrm{L}^{-1}$, with correlation coefficients $\left(r^{2}\right)$ greater than 0.997. The LODs and LOQs were found to be 1.69 and $5.63 \mathrm{ng} \mathrm{L}^{-1}$ for vitamin $\mathrm{C}$ and 2.05 and $6.83 \mathrm{ng} \mathrm{L}^{-1}$ for folic acid, respectively. The repeatability was studied for six replicate analyses of the spiked samples (at concentrations $25 \mathrm{ng} \mathrm{L}^{-1}$ of vitamin $C$ and folic acid) under the same operational parameters. The relative standard deviations (RSDs) were satisfactory, ranging from $3.7 \%$ and $5.3 \%$ for the vitamin $\mathrm{C}$ and folic acid, respectively, showing the good repeatability of the proposed method. The obtained results are summarized in Table 1. The repeatability (intra-day) and reproducibility (interday) precision of the UA-DLLME were assessed according to the results of six replicates at level of $25 \mathrm{ng} \mathrm{mL}^{-1}$ of vitamin $C$ and folic acid for six consecutive days. The values of intra-day relative standard deviation (RSD) and inter-day RSD were 6.4 and $6.8 \%$, respectively. The chromatograms of the blank urine and spiked blank urine samples at three concentration levels are shown in Fig. 3. To demonstrate the superiority of the presented method, a comparison between the important analytical parameters of the developed UA-DLLME and those reported in the literature was made as summarized in Table $2^{19-21}$.

\section{Analysis of actual samples}

To evaluate the performance and applicability of UA-DLLME method for the extraction and subsequent determination of vitamin $\mathrm{C}$ and folic acid from actual urine samples was examined using calibration curves. These samples were pretreated as described in section 2.4, extracted using UADLLME method and analyzed by HPLC-UV. These samples were spiked with the standards of vitamin C and folic acid at the concentration of 15.0, 30.0 and $45.0 \mathrm{ng} \mathrm{mL}^{-1}$. For each concentration, three replicate experiments were undertaken and the results are given in Table 3. The extraction recovery for the spiked real samples was in the range of $94.3 \%$ and 98. $2 \%$ and the RSDs were between $3.8 \%-5.2 \%$. Obtained results (Table 3 ) indicate the applicability and efficiency of proposed UA-DLLME-HPLC-UV for a sensitive, fast, reproducible and simple extraction and determination of vitamin $\mathrm{C}$ and folic acid in actual urine samples.

\section{CONCLUSION}

A new method has been proposed for the simultaneous determination trace levels of vitamin $C$ and folic acid in human urine samples using HPLC after optimization by UA-DLLME method. Optimum conditions were found at $100 \mu \mathrm{L}$ of $\mathrm{CCl}_{4}, 50 \mu \mathrm{L}$ of methanol, $0.05 \%(\mathrm{w} / \mathrm{v})$ of $\mathrm{NaCl}$ and $4 \mathrm{~min}$ for sonication time. The advantages of thismethod include high recovery, simplicity of operation, good repeatability and reproducibility, with good LODs. Finally, because of the low organic solvent consumption, the presented UA-DLLME proved an inexpensive and environmentally friendly method.

\section{ACKNOWLEDGEMENTS}

The authors would like to acknowledgements the support of Abadan School of Medical Sciences for financial support of this work (Project ID: 95ST-0059 and code of ethics:IR.ABADANUMS. RES.1395.83).

\section{REFERENCES}

1. Polk, A.; Flanagan, T. L.; \& Van Loon, E. J. Rapid method for determination of ascorbic acid in urine. Clinical chemistry. 1960, 6, 558563.

2. Chamkouri, N.; Khodadoust, S.; Ghalavandi, F. Solid-Phase Extraction Coupled with HPLC-DAD for Determination of B Vitamin Concentrations in Halophytes. Journal of chromatographic science, bmv080.2015, 53, 1720-1724.

3. Gong, W.; Dou, Z. Y.; Liu, P.; Cai, X.Y.; \& He, X. Q. Simultaneous determination of dopamine, ascorbic acid by polyethylene oxide (PEO) covalently modified glassy carbon electrode. Journal of Electroanalytical Chemistry. 2012, 666, 62-66. 
4. Ghasemi, J.; Seifi, S.; Sharifi, M.; Ghorbani, R.; Amini, A. Simultaneous kinetic spectrophotometric determination of ascorbic acid and L-cysteine by $\mathrm{H}$-point standard addition method. Microchimica Acta. 2004, 148, 259-265.

5. Maki, T.; Soh, N.; Nakano, K.; Imato, T. Flow injection fluorometric determination of ascorbic acid using perylenebisimide-linked nitroxide. Talanta. 2011, 85, 1730-1733.

6. Li, B.; Wang, D.; Xu, C.; Zhang, Z. Flowinjection simultaneous chemiluminescence determination of ascorbic acid and L-cysteine with partial least squares calibration. Microchimica Acta. 2005, 149, 205-212.

7. Pires, C. K.; Lavorante, A. F.; Marconi, L. M.; Meneses, S. R.; Zagatto, E. A. A multipumping flow system for chemiluminometric determination of ascorbic acid in powdered materials for preparation of fruit juices. Microchemical journal. 2006, 83, 70-74.

8. Dinelli, G.; Bonetti, A. Micellar electrokinetic capillary chromatography analysis of water soluble vitamins and multi vitamin integrators. Electrophoresis. 1994, 15, 1147-1150.

9. Fotsing, L.; Fillet, M.; Bechet, I.; Hubert, P.; Crommen, J. Determination of six watersoluble vitamins in a pharmaceutical formulation by capillary electrophoresis. Journal of pharmaceutical and biomedical analysis.1997, 15, 1113-1123.

10. Gavrilenko, N. A.; Mokrousov, G. M.; Dzhiganskaya, O. V. An optical sensor for the determination of ascorbic acid. Journal of Analytical Chemistry. 2004, 59, 871-874.

11. Khan, M.I.; Iqbal, Z.Simultaneous determination of ascorbic acid, aminothiols, and methionine in biological matrices using ion-pairing RPHPLC coupled with electrochemical detector. Journal of Chromatography B. 2011, 879, 2567-2575.

12. Markopoulou, C. K.; Kagkadis, K. A.; Koundourellis, J. E. An optimized method for the simultaneous determination of vitamins B 1, B 6, B 12, in multivitamin tablets by high performance liquid chromatography. Journal of pharmaceutical and biomedical analysis. 2002, 30, 1403-1410.

13. Rezaee, M.; Assadi, Y.; Hosseini, M. R. M.; Aghaee, E.; Ahmadi, F.; Berijani, S.
Determination of organic compounds in water using dispersive liquid-liquid microextraction. Journal of Chromatography A. 2006, 1116, 1-9.

14. Ghaedi, M.; Roosta, M.; Khodadoust, S.; Daneshfar, A. Application of Optimized VortexAssisted Surfactant-Enhanced DLLME for Preconcentration of Thymol and Carvacrol, and Their Determination by HPLC-UV: Response Surface Methodology. Journal of chromatographic science, bmu216. 2015, 53, 222-1231.

15. De Castro, M. L.; Priego-Capote, F. Ultrasoundassisted preparation of liquid samples. Talanta. 2007, 72, 321-334.

16. Khodadoust, S.; Ghaedi, M. Application of response surface methodology for determination of methyl red in water samples by spectrophotometry method. Spectrochimica Acta Part A: Molecular and Biomolecular Spectroscopy. 2014, 133, 87-92.

17. Pebdani, A. A.; Shabani, A. M. H.; Dadfarnia, S.; Talebianpoor, M. S.; Khodadoust, S. Preconcentration of valsartan by dispersive liquid-liquid microextraction based on solidification of floating organic drop and its determination in urine sample: Central composite design. Journal of separation science. 2016, 39, 1935-1944.

18. Pebdani, A. A.; Khodadoust, S.; Talebianpoor, M. S.; Zargar, H. R.; Zarezade, V. Preconcentration and determination of chlordiazepoxide and diazepam drugs using dispersive nanomaterial-ultrasound assisted microextraction method followed by high performance liquid chromatography. Journal of Chromatography B. 2016, 1008, 146-155.

19. Zheng, X. H.; Jiang, L. Y.; Zhao, L. T.; Zhang, Q. Y.; Ding, L. Simultaneous quantitation of folic acid and 5-methyltetrahydrofolic acid in human plasma by HPLC-MS/MS and its application to a pharmacokinetic study. Journal of Pharmaceutical Analysis. 2015, 5, 269-275.

20. Jin, P.; Xia, L.; Li, Z.; Che, N.; Zou, D.; Hu, X. Rapid determination of thiamine, riboflavin, niacinamide, pantothenic acid, pyridoxine, folic acid and ascorbic acid in Vitamins with Minerals Tablets by high-performance liquid chromatography with diode array detector. 
Journal of Pharmaceutical and Biomedical analysis. 2012, 70, 151-157.

21. Ferin, R.; Pavão, M. L.; Baptista, J. Rapid, sensitive and simultaneous determination of ascorbic and uric acids in human plasma by ion-exclusion HPLC-UV. Clinical biochemistry. 2013, 46, 665-669. 